\title{
Fat Is Sexy for Females but Not Males: The Influence of Body Reserves on Reproduction in Snakes (Vipera aspis)
}

\author{
Fabien Aubret, $*$ Xavier Bonnet, $\dagger^{, 1}$ Richard Shine, $\neq$ and \\ Olivier Lourdais* \\ ${ }^{*}$ Centre d'Etudes Biologiques de Chizé CNRS, 79360 Villiers en Bois, France; \\ +Centre d'Etudes Biologiques de Chizé CNRS et Conseil Général des Deux Sèvres, \\ 79360 Niort, France; and $\ddagger$ Biological Sciences A08, University of Sydney, \\ New South Wales 2006, Australia
}

Received February 12, 2001; revised December 15, 2001; accepted January 7, 2002

Reproduction is energetically expensive for both sexes, but the magnitude of expenditure and its relationship to reproductive success differ fundamentally between males and females. Males allocate relatively little to gamete production and, thus, can reproduce successfully with only minor energy investment. In contrast, females of many species experience high fecundity-independent costs of reproduction (such as migration to nesting sites), so they need to amass substantial energy reserves before initiating reproductive activity. Thus, we expect that the relationship between energy reserves and the intensity of reproductive behavior involves a threshold effect in females, but a gradual (or no) effect in males. We tested this prediction using captive vipers (Vipera aspis), dividing both males and females into groups of high versus low body condition. Snakes from each group were placed together and observed for reproductive behavior; sex-steroid levels were also measured. As predicted, females in below-average body condition had very low estradiol levels and did not show sexual receptivity, whereas males of all body condition indices had significant testosterone levels and displayed active courtship. Testosterone levels and courtship intensity increased gradually (i.e., no step function) with body condition in males, but high estradiol levels and sexual receptivity were seen only in females with body reserves above a critical threshold. $\odot 2002$ Elsevier Science (USA)

Key Words: capital breeding; hormones; sexual behaviors; snakes; threshold; Vipera.

\footnotetext{
${ }^{1}$ To whom correspondence should be addressed. Fax: 3354909 65 26. E-mail: bonnet@cebc.cnrs.fr.
}

The energetics of reproduction has been a central theme in the ecological study of life history variation (Hirshfield and Tinkle, 1975; Morris, 1987, 1992; Winkler and Wallin, 1987; Stearns, 1992; Monaghan and Nager, 1997), and more recently this topic has become an important focus in behavioral endocrinology (Cherel, Mauget, Lacroix, and Gilles, 1994; Bronson, 1998). It is obvious that organisms cannot reproduce in the total absence of energy reserves (Frish, 1978; Frish and McArthur, 1974), but the relationship between the amount of energy reserves and reproductive output (or effort) is complex and varies among species. In some species there is a linear relationship between energy reserves and reproductive output. In others there appears to be no discernible relationship (e.g., if clutch and offspring sizes are fixed) or a complex nonlinear relationship between the two variables. For example, many organisms are "capital breeders" that rely on previously gathered energy stored in the form of body reserves (i.e., fat bodies, proteins) rather than on current energy intake to fuel the energetically costly process of reproduction (Drent and Daan, 1980; Jönsson, 1997; Bonnet, Bradshaw, and Shine, 1998). In such species, life history theory predicts that a threshold level of energy reserves is necessary for a reproductive cycle to begin, rather than a linear relationship in which an increment in energy availability adds an increment in reproductive output (Schaffer, 1974; Bull and Shine, 1979; Stearns, 1992). Several empirical studies provide evidence for nonlinear relationships between energy reserves and reproductive effort (e.g., Larsen, 1980; Roff, 1981; Reznick and Yang, 1993; Young, 1990; Madsen and Shine, 1999). 
In many species, female reproduction requires a considerable "startup" investment. This is critical in species in which there is a substantial cost to activities such as nesting and gestation (e.g., added vulnerability to predation, added energetic costs) and when the magnitude of these costs is relatively independent of the female's clutch size. If these costs are high, the most cost-effective strategy for a female would be to delay reproduction until a large clutch can be produced (Bull and Shine, 1979). European eels are typical examples of animal species that face high fecundityindependent costs: for spawning, females leave freshwater rivers and cross the Atlantic Ocean. The distance (thousands of kilometers) they have to cover, hence the risk of predation and the energetic demands for swimming, is relatively independent of the size of their clutch. On average, female eels postpone migration and vitellogenesis over 10 years during which they build up very large body reserves (mostly fat bodies) that are used later to produce thousands of eggs in a single reproductive bout. Similarly, many female insects are highly vulnerable to predation during reproduction, simply because they leave a relatively secure shelter to mate and/or disperse. Again, the high survival cost of reproduction is more closely related to a discrete behavioral change rather than to the size of the clutch. To minimize the costs independent of fecundity, theory suggests that females of these species should produce a large number of offspring per reproductive bout. Because vitellogenesis is energetically demanding, it would be predicted that females of these species would exhibit a high threshold level of energy reserves below which reproductive processes would be inhibited. Importantly, such a threshold would greatly exceed the minimal body reserves necessary for survival, below which reproduction is inhibited in almost all species.

For males of many species, life-history theory predicts a different relationship between energy and reproduction than that predicted for females. In many taxa, males do not care for the offspring, nor do they engage in energetically expensive or dangerous premating activities. In such species, the primary energetic expenditure by males is for the production of gametes. Following this relatively minor initial investment, a male can then facultatively adjust his subsequent level of expenditure in activities such as mate searching and male-male rivalry.

We have studied an organism that exhibits just this kind of male-female divergence in energetic aspects of reproduction. Female vipers (Vipera aspis) experience high fecundity-independent costs of reproduction, both in terms of survival (Bonnet, Naulleau, and Lourdais, 2000a; Bonnet, Naulleau, Shine, and Lourdais, 2000c) and in terms of energetics during gestation (i.e., decrease in food intake) (Lourdais, Bonnet, and Doughty, 2001). Females reproduce on a 2- to 4-year cycle (Saint Girons, 1957; Naulleau, Bonnet, VacherVallas, Shine, and Lourdais, 1999). The intervening "nonreproductive" years are spent in accumulating energy; female vipers delay reproduction until they have substantial energy reserves (Saint Girons, 1957; Naulleau and Bonnet, 1996; Bonnet et al., 2000a; Bonnet, Naulleau, Shine, and Lourdais, 2000b, 2001a). Although the role of energy reserves in male reproduction has not been investigated in detail in this species, there is no male territoriality (Vacher-Vallas, 1997). Hence, we may predict that:

1. Female vipers will not initiate reproduction (as judged by estradiol levels, sexual receptivity, or production of offspring) unless they exceed a certain minimal level of body reserves for vitellogenesis (lipids stored in the fat bodies and in the liver, proteins stored in the liver and in the muscles, calcium and phosphorus stored in the vertebrae, etc.) (Bonnet, 1996; Bonnet, Naulleau, and Mauget, 1994); whereas

2. Male vipers will initiate reproduction (as judged by testosterone levels, courtship behavior and copulation) either regardless of their body condition, or with a gradual (rather than threshold) relationship between the two variables.

The present experiments were designed to test these predictions by measuring sex behavior and plasma steroid concentrations in captive female and male vipers that differed in their body condition.

\section{MATERIALS AND METHODS}

\section{Study Species}

The asp viper (Vipera aspis) is a venomous snake that occurs from central France through to southern Europe (Naulleau, 1997). The snakes in our study came from western France (subspecies Vipera aspis aspis). The total body length averages $55 \mathrm{~cm}$ in adults with a body mass of approximately $100 \mathrm{~g}$. Vitellogenesis starts immediately after hibernation in early March and extends until mid-June (Bonnet et al., 1994). Gestation follows, with parturition in late August to mid-September (Bonnet et al., 2001a). The production of viable offspring takes approximately 6 months. During this time females invest large amounts of body 
reserves to fuel vitellogenesis and gestation (Bonnet et al., 1994). Reproductive females eat during vitellogenesis but such energy intake is mostly devoted to the offspring (Bonnet et al., 2001a). After parturition they are very emaciated and they need 1 to 4 years to accumulate enough body reserves to regain the condition threshold for reproduction (Saint Girons, 1957; Naulleau and Bonnet, 1996; Bonnet et al., 2000a-c). Mating occurs within the first half of vitellogenesis, during the period from the female's winter emergence to the end of April (Naulleau et al., 1999; VacherVallas, Bonnet, and Naulleau, 1999). In males, most of the reproductive effort is concentrated within a 2- to 3-month period comprising the premating (February) and mating (March-April) phases. Reproducing male vipers display high levels of plasma testosterone and thyroxin (Naulleau, Fleury, and Boisson, 1987). Because they stop feeding during the mating season (Saint Girons, 1996; Vacher-Vallas, 1997), they also show a strong decrease in body mass. Thus, body reserves are necessary to fuel the reproductive behaviors of male vipers (Vacher-Vallas, 1997), as has been documented in a closely related species, the adder (Madsen and Shine, 1993; Madsen, Shine, Loman, and Håkansson, 1993).

\section{Experimental Design}

We captured 34 adult asp vipers in the wild, soon after they emerged from their overwintering sites (February and March 1999). Of these snakes, 18 were males and 16 were females. The snakes were measured (total and snout-vent lengths) and weighed (to the nearest $0.1 \mathrm{~g}$ ). Some females were caught with more or less digested prey in the stomach. In such cases weighing of the snakes was postponed until digestion was complete (3-6 days). We marked each individual by scale clipping and by painting symbols on the back.

Body condition was calculated as the residual scores from the regression of log transformed body mass against log body length (Jayne and Bennett, 1990). Dissections have shown that most of the variance in body condition index is explained by variations in the fat stores in males (Bonnet, 1996) and by a combination of fat stores and liver mass in females (Bonnet and Naulleau, 1994; Bonnet, 1996). Consequently, the body condition of females and males was calculated separately. We selected snakes with a range of body condition that encompassed the usual variation observed in the wild (Bonnet, 1996; Naulleau and Bonnet, 1996). Thus, some of the captured snakes were emaciated,

\section{TABLE 1}

Multiple Regression Analyses Including Snout-Vent Length and Body Mass Enable Explanation of a Large Proportion in the Variance of the Main Body Reserves of Autopsied Snakes ${ }^{a}$

\begin{tabular}{cllll}
\hline \multicolumn{1}{c}{ Trait } & Sex & $r^{2}$ & $N$ & $P$ \\
\hline Fat bodies $(\mathrm{g})$ & Females & $72 \%$ & 85 & 0.001 \\
& Males & $59 \%$ & 37 & 0.001 \\
Liver $(\mathrm{g})$ & Females & $75 \%$ & 71 & 0.001 \\
\multirow{3}{*}{ Muscles $(\mathrm{g})$} & Males & $70 \%$ & 37 & 0.001 \\
& Females & $78 \%$ & 71 & 0.001 \\
& Males & $93 \%$ & 37 & 0.001 \\
\hline
\end{tabular}

${ }^{a}$ The coefficients obtained (not displayed in this table) in the analysis have been used to estimate the body reserves of the living snakes involved in the experiment (see Table 2).

some were intermediate in condition, and some had large body reserves. Because a large sample (122 asp vipers: 85 females and 37 males) of accidentally killed asp vipers has been previously autopsied (see Bonnet, 1996; Bonnet et al., 1998a, for details of the autopsies), and because snakes exhibit a highly simplified morphology (Bonnet et al., 1998a), we were able to estimate the mass of the body reserves of the snakes involved in the present experiment. The mass of the major body reserves, fat bodies, liver, and skeletal muscles was weighed to the nearest $0.1 \mathrm{~g}$. External morphology of snakes is easily characterized by their body length and their body mass. Including these two variables in multiple regressions enables comparison of living and autopsied individuals and provides a satisfactory estimate for the mass of the fat bodies, liver, and muscles (Bonnet, 1996; Naulleau and Bonnet, 1996). Indeed, the analyses explain a large proportion in the variance of the main body reserves of the snakes (Table 1).

The snakes were bled immediately after initial capture by intracardiac puncture. To minimize the risk of lethal tissue lesion in fragile parts of the heart, we systematically targeted the tip of the ventricle. The ventricle was located by careful palpation, and 200 to $350 \mu$ l of blood was sampled into a sterile syringe (without heparinization). Each animal was bled only once and none of the snakes exhibited any overt problems following blood sampling. The blood was immediately centrifuged and the plasma frozen and stored at $-25^{\circ} \mathrm{C}$ until assays were conducted. Plasma levels of testosterone and estradiol were measured by radioimmunoassay on a 50- $\mu$ l plasma sample after extraction with $0.5 \mathrm{ml}$ of diethyl ether (mean extraction efficiency was $0.98 \pm 0.10$ ). The sensitivity of the assay was 7.8 and $1.9 \mathrm{pg} /$ tube for testosterone and estradiol, 
respectively. Inter- and intraassay variations were 12 and $5 \%$, respectively. The highly specific rabbit antiserum was provided by Sigma; cross-reaction with other steroids was low (percentage of cross-reactivity at $B / B_{0}$ with other steroids was always $<10 \%$ ) (see Naulleau et al., 1987; Bonnet et al., 1994, for further details). Importantly, sex steroids have been assayed in the asp viper using chromatographic separation on Sephadex columns (Saint Girons, Bradshaw, and Bradshaw, 1993). The results showed that in males, plasma levels of DHT (the hormone that could potentially invalidate some of our results) are minor in comparison to testosterone variations; furthermore changes in plasma levels of DHT are parallel to testosterone variations. In addition Silastic implants fitted with testosterone and placed under the skin stimulated sexual behavior in captive male asp vipers (X.B. et al., unpublished data). Saint Girons et al. (1993) and Bonnet et al. (1994, 2001b) also demonstrated that variations in plasma levels of estradiol represent the major changes of sex steroids in spring, precisely the period during which we carried out the experiment. High plasma levels of estradiol are apparently associated with sexual behaviors (Saint Girons et al., 1993), and injection of exogenous estradiol provokes vitellogenesis in nonreproductive females (Bonnet et al., 1994). Overall, empirical and experimental data strongly support the notion that testosterone in males and estradiol in females are likely to be the major sex steroids that influence reproduction (behaviors and mobilization of body reserves) during the mating season in the asp viper.

For behavioral observations, the vipers were allocated to four groups based on sex and body condition (high-body-condition females, low-body-condition females, high-body-condition males, low-body-condition males) (Table 1). We crossed the four groups into the four available combinations: two sexes $\times$ two body-condition classes. One male was placed with one female, and we noted the behaviors expressed by each individual. In natural conditions, female vipers are sometimes courted by more than one male (personal observation). In such circumstances, a male's courtship behavior may reflect not only his own physiological state and that of the female, but also behavioral interactions among males (e.g., Schuett, 1997; O'Connor, and Mason, 2000a; Shine, Olsson, Moore, Le Master, Greene, and Mason, 2000b). To minimize such confounding influences, we adopted the simplest experimental design.

Behaviors were recorded during the day ( $V$. aspis is diurnal) in four indoor enclosures situated in an air- conditioned room $\left(20^{\circ} \mathrm{C}\right)$. Each indoor enclosure had a surface of $1.5 \mathrm{~m}^{2}(1.7 \times 0.87 \mathrm{~m})$. To facilitate locomotion we covered the surface with an artificial grass substratum. A stone was also placed in each enclosure, along with small water dishes. We artificially created a thermal gradient $12 \mathrm{~h}$ /day within each enclosure with a radiant heater placed $0.8 \mathrm{~m}$ above the edge of the enclosure. To limit disturbance and stress due to the presence of the observer, behavioral data were recorded by a stationary observer looking through a net placed above the enclosure. Four pairs of snakes were monitored per day. The snakes were placed into the indoor enclosures the night before, to allow them to settle down prior to observation. Each pair of snakes was observed during the whole daytime: 11 data points (focal surveys) were recorded during this period. Focal surveys lasted $5 \mathrm{~min}$ each, and were conducted once per hour. Between each day of observations, one day was necessary to clean the enclosures, removing any residual pheromone tracks or other chemical cues that may influence snake behavior.

During our observation periods the snakes either did not display any obvious behavior (i.e., a snake alone and immobile in a corner of the enclosure), or were observed alone during displacements, or were observed as male and female together. In the latter case, we distinguished between behaviors related to sexual activity (courtship and mating) versus those that might involve nonsexual activity (i.e., a male can be coiled with a female simply as a result of basking under a hot spot). Below, we briefly describe the system we used to score the behaviors.

The succession of sexual behaviors in a male viper during courtship has been categorized in terms of his increasing level of interest toward a particular female (Saint Girons, 1952; Moore and Lindzey, 1992; VacherVallas et al., 1999). The sequence of sexual behaviors documented in the asp viper is classic for snakes, and corresponds to the description provided by Gillingham (1977).

Bh1: simple contact between male and female.

Bh2: male coiled with (generally above) the female.

Bh3: male jerking on the female. The male frequently touches the female with his head, rubbing his chin on the top and side of her body, with many short tongue-flicks.

Bh4: male attempts to lift the female's tail (tailsearch copulation attempt). This behavior was displayed only when the female demonstrated interest in the male (see Vacher-Vallas et al., 1999).

Bh5: copulation. 
In snakes, female sexual behaviors are less obvious than those of the male. Forced insemination is impossible, however, and thus both the female's attractiveness and cooperation are essential if mating is to occur (Devine, 1984).

Bh1: simple contact between female and male.

Bh2: female escaping. The female moves away suddenly, for a short distance, and then stops. This behavior has been interpreted as a "sexual game" (both in captivity and in the field) (Saint Girons, 1996; Vacher-Vallas, 1997).

Bh3: rapid tail movements, from side to side. These are typical of sexually receptive female snakes.

Bh4: female raises her tail and sometimes opens the vent, indicating the imminence of copulation.

Bh5: copulation.

In both sexes, only Bh3, Bh4, and Bh5 can be readily attributed to sexual activity. Successful copulation including transmission of sperm was checked at the end of the observation period by massage of the female's abdomen (Fukada, 1959; Naulleau et al., 1999). Our experimental design does not allow us to tease apart the respective contributions of female attractiveness and male motivation on the expression of the sexual behaviors exhibited by each snake pair. However, the resolution of this problem was not our goal. We simply focused on the effect of each snake pair combination (low versus high body condition) on the sexual behavior exhibited by each snake. For instance, does a male in poor body condition display sexual behavior when placed with a given female whatever her body condition (her attractiveness)?

Between behavioral experiments (see below), the snakes were kept in outdoor enclosures $\left(8 \mathrm{~m}^{2}\right.$ under natural climatic conditions) that represented a natural habitat. Each cage contained artificial dens, several shelters, and sunny places and the soil was covered by natural vegetation. Water was provided ad libitum, and food (laboratory mice) was offered during the course of the study in late March. The snakes were released at their exact place of capture at the end of the experiments in late April and May.

\section{Analyses}

Behaviors. Because of the possibility that individual females may elicit more or less courtship from different individual males (Shine et al., 2000c), we obtained repeated observations on each snake. That is, a single male was trialed with several females, and a single female was trialed with several males. This procedure should overcome biases associated with specific mate preferences but we cannot treat the resulting data as independent (because we tested each individual several times). To avoid pseudoreplication, we based our analyses on a single data point for each individual: the maximal behavioral score recorded over the entire experiment. We scored behaviors as follow: 0 for absence of detectable behavior, and then 1 to 5 from Bh1 to Bh5. These behaviors constitute a suite that has been observed both in captivity and in the wild in different species (Gillingham, 1977; Walker and Ford, 1996; Schuett and Gillingham, 1988). For example Bh5 is at least the sum of all the behaviors from Bh1 to Bh5. We never observed any short cut in the sequence, that is, a male trying to copulate directly without all the preceding behaviors. Although not perfect, such scores should reflect the level of the snake's sexual "motivation" (that may emerge from a complex combination of partner attractiveness, response to courtship, and internal "level of motivation").

All of our experiments were conducted during the natural mating period (March-April). Preliminary analyses suggest that variation in the exact timing of trials within this period did not have a significant effect on courtship intensity or responses. Most of the individuals participated in three tests from the first capture to the end of the experiment. For each period we scored the maximal sexual score on our behavioral scale. Repeated-measures ANOVA on the same individuals revealed no significant shifts in behavioral scores through time (specific effect of time: $R$ Rao $=$ $0.55, d f=2,8, P=0.60$ in males; $R$ Rao $=0.17, d f=$ $2,6, P=0.85$ in females). Thus, the exact timing of the trials appeared to have had little effect on the expression of sexual behavior.

Hormonal data. Our data on steroid levels in the plasma typically fell into two major categories: virtually zero, and very high. Thus, we recorded levels ranging from $<2$ to $1000 \mathrm{pg} /$ tube. Even after log transformation, the distribution of steroid levels was not normal. We used the nonparametric median test to compare plasma values obtained in low-condition versus high-condition groups. Using this method, we simply count the number of cases in each sample that fall above or below the common median, and compute the $\chi^{2}$ value for the resulting $2 \times k$ contingency table. The major disadvantage inherent in such a crude version of nonparametric tests to compare two samples is that the power of the analysis is lowered. The compensating advantage, however, is that the analysis is less sensitive to outliers. The median test is particu- 
TABLE 2

One-Factor ANOVAs Indicate that Females and Males from the High versus Low Condition Groups Did Not Differ in SVL ${ }^{a}$

\begin{tabular}{|c|c|c|c|c|c|c|}
\hline Trait & Sex & High condition & Low condition & $F$ & $d f$ & $P$ \\
\hline \multirow[t]{2}{*}{ SVL } & Females & $49.7 \pm 3.8(10)$ & $50.2 \pm 3.1(6)$ & 0.06 & 1,14 & 0.81 \\
\hline & Males & $50.9 \pm 9.7(11)$ & $46.6 \pm 9.0(7)$ & 0.90 & 1,16 & 0.36 \\
\hline \multirow[t]{2}{*}{ Body mass (g) } & Females & $101.2 \pm 34.0$ & $66.7 \pm 21.2$ & & & \\
\hline & Males & $101.5 \pm 52.1$ & $64.1 \pm 42.5$ & & & \\
\hline \multirow[t]{2}{*}{ Body condition } & Females & $0.167 \pm 0.096$ & $-0.254 \pm 0.088$ & 76.6 & 1,14 & 0.0000 \\
\hline & Males & $0.076 \pm 0.058$ & $-0.122 \pm 0.134$ & 19.10 & 1,16 & 0.0005 \\
\hline \multirow[t]{5}{*}{ Fat bodies (g) } & Females & $10.6 \pm 5.6$ & $3.3 \pm 2.3$ & & & \\
\hline & & $9.9 \pm 5.6 \%$ & $4.2 \pm 2.8 \%$ & & & \\
\hline & & [11.3\%] & [4.9\%] & & & \\
\hline & Males & $6.8 \pm 3.6$ & $3.2 \pm 2.8$ & & & \\
\hline & & $6.8 \pm 0.7 \%$ & $5.0 \pm 2.1 \%$ & & & \\
\hline \multirow[t]{5}{*}{ Liver $(\mathrm{g})$} & Females & $6.4 \pm 3.0$ & $3.1 \pm 1.6$ & & & \\
\hline & & $6.2 \pm 0.7 \%$ & $4.2 \pm 1.4 \%$ & & & \\
\hline & & {$[7.5 \%]$} & {$[6.2 \%]$} & & & \\
\hline & Males & $4.8 \pm 3.3$ & $2.8 \pm 2.7$ & & & \\
\hline & & $4.3 \pm 1.3 \%$ & $3.7 \pm 1.4 \%$ & & & \\
\hline \multirow[t]{4}{*}{ Muscles (g) } & Females & $39.3 \pm 11.5$ & $28.1 \pm 7.5$ & & & \\
\hline & & $39.2 \pm 1.4 \%$ & $42.9 \pm 3.2 \%$ & & & \\
\hline & Males & $46.3 \pm 24.4$ & $28.9 \pm 19.4$ & & & \\
\hline & & $45.2 \pm 10.2 \%$ & $44.6 \pm 11.0 \%$ & & & \\
\hline
\end{tabular}

\footnotetext{
${ }^{a}$ Our experimental design, however, created very significant differences in body condition and body reserves between these two categories. Values are expressed as means \pm SD; sample size is indicated in parentheses. Body reserve estimates are given as both absolute and relative (\% of body mass) masses; values in square brackets refer to estimates made with an independent data set on both reproductive and nonreproductive females (Naulleau and Bonnet, 1996).
}

larly useful when the scale contains artificial limits (which is the case in our experimental design with the low-condition versus high-condition groups) and when many cases fall at either extreme of the scale (undetectable versus high plasma values of steroids, see results). In such a situation, the median test is the most appropriate method for comparing samples (Statistica for Windows, 1995).

Threshold effects. One of our primary questions was to examine if thresholds exist in the expression of behaviors, and if such effects are related to hormonal levels. If a threshold effect exists, we should observe high scores (for sexual behaviors or plasma steroid levels) only in individuals with body condition above a critical value. However, such a pattern (or the absence of such a pattern) might also result from random effects. We used ad hoc randomization procedures (Crowley, 1992; Guillemain, Loreau, and Daufresne, 1997) to calculate the probability that the patterns we observed would be expected under the null hypothesis of no threshold value: that is, the distribution between the ordinates and associated abscissas of the points (e.g., in Fig. 2) should be random. We tested this possibility by resampling the original data. We randomly reassigned ordinates to abscissas and calcu- lated the probability of finding a pattern as extreme as that observed (see Fig. 2 where we found no point in the area limited by the line below the threshold ( $x$ axis) and the lines represented by the level of detectable sexual behavior or the levels of detection of steroid in our assay ( $y$ axis)).

\section{RESULTS}

\section{Morphology}

The morphological characteristics of the four groups of snakes are given in Table 2. Within each sex, average snout-vent lengths did not differ between the high-body-condition and low-body-condition groups (Table 1). In contrast, body condition indices differed significantly. Overall, the composition of the four groups enabled us to examine the effect of body reserves on reproduction, independently of body size.

\section{Body Reserve Estimates}

Table 2 provides estimates of the body reserves of the four groups of snakes. As expected, the mass of the 


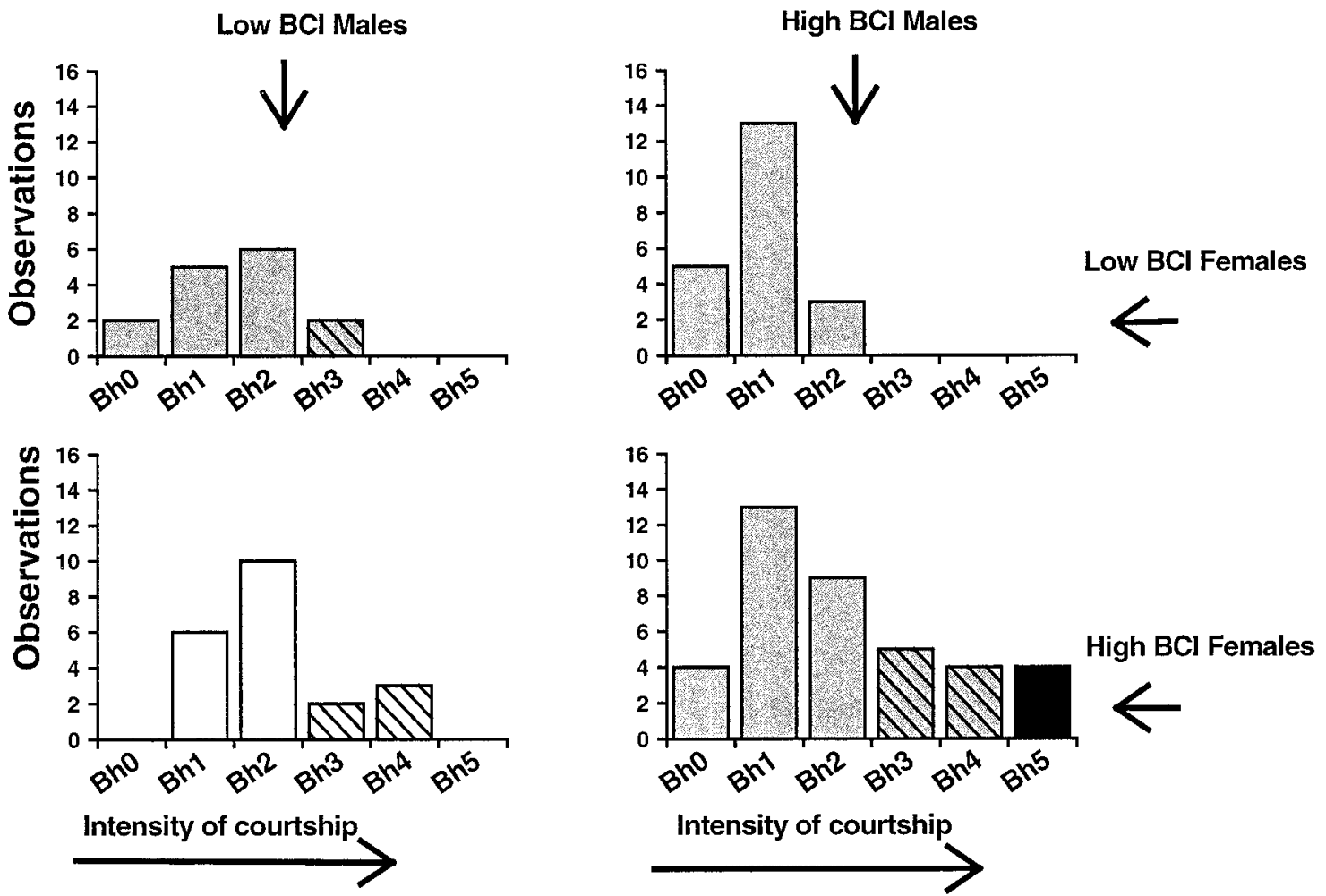

FIG. 1. Effect of body condition on sexual behaviors in captive snakes. The highest value on the behavioral scale from zero to mating (Bh0 to Bh5, see text) exhibited by 96 different pairs of snakes was recorded for four experimental groups of snakes based on sex and body condition.

estimated fat bodies varied greatly over the range of body condition (from virtually $0 \mathrm{~g}$ to more than $22 \mathrm{~g}$ ), and snakes in high body condition presented higher mean absolute and relative values. The average amounts of fat bodies estimated in the females involved in the present experiment are consistent with those calculated on a larger sample of vitellogenic and nonreproductive females monitored in the field (Table 2) (Naulleau and Bonnet, 1996). The same pattern was observed for the mass of the liver (Table 2). The absolute estimated mass of the carcass (i.e., muscle mass) was higher in snakes in better condition; however, the relative estimated mass ( $\%$ of total body mass) showed the reverse trend. This simply suggests that snakes in poor body condition were relatively lean, supporting the notion that fat bodies ( + the liver in females) constitute the major body reserves in these animals (Table 2). Importantly, both females and males from the low-body-condition groups were not necessarily very emaciated (i.e., close to a level of body condition critical for survival) as indicated by the persistence of significant mean estimated fat bodies on average (Table 2; range from 0.00 to $6.25 \mathrm{~g}$ in females and 0.95 to $9.45 \mathrm{~g}$ in males).

\section{Effect of Different Group Combinations on Sexual Behaviors}

In the course of the experiment we conducted 1056 focal observations on 96 different pairs of snakes. Among these 96 different pairs, 11 did not exhibit any detectable behavior; 65 expressed behaviors that we could not classify unambiguously as either "sexual" or "nonsexual"; and 20 exhibited typical sexual behaviors (Fig. 1). Among the latter, four different pairs involving eight different snakes were observed to copulate (introduction of hemipenes + transmission of sperm). A Kruskal-Wallis ANOVA with the four group combinations (i.e., interaction of male $\times$ female body condition) as the factor and the maximal behavioral score expressed by each snake pair (Bh0 to Bh5) as the dependent variable shows that the sexual activity of the snakes varied significantly among groups $\left(H_{3}=16.33, N=96, P=0.001\right)$ (Fig. 1$)$.

\section{Relationship Between Snake Body Condition and Sexual Behaviors}

Courtship attained a greater intensity in the combinations that involved high-condition females (Kruskal- 

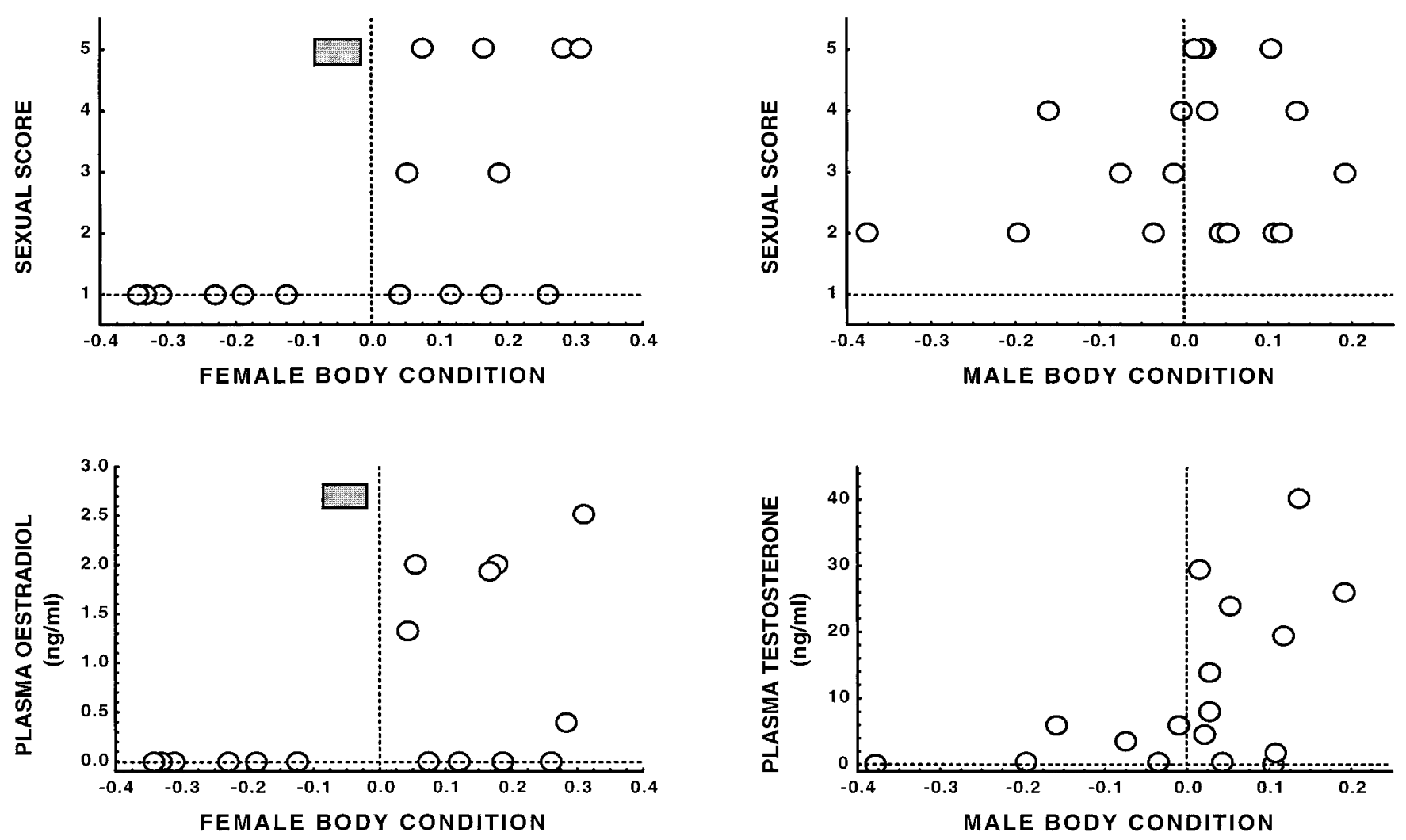

FIG. 2. Maximal sexual score and plasma levels of estradiol (females) or testosterone (males) of the 16 females and 18 males involved in the experiments plotted against individual's body condition. The range of body condition values containing the body condition threshold for reproduction observed in the field on large data sets (several hundred individuals) (Naulleau and Bonnet, 1996; Naulleau et al., 1999) is indicated by the gray boxes.

Wallis ANOVA with female condition as the factor: $H_{1}=$ $12.1, N=96, P=0.0005$; this analysis performed with each individual represented only once to avoid pseudoreplication led to similar results: Kruskal-Wallis ANOVAs with body condition as the factor and sexual behavior as the dependent variable gave $H_{1}=4.85, \mathrm{~N}=$ $16, P=0.03$ ) (Figs. 1 and 2). Notably, female responses to courtship (Bh4: tail search copulation attempt, and Bh5: mating plus preceding behaviors) were observed in only six females, all of them "high-condition" animals. Likewise, copulation occurred only in experimental combinations involving females with a high-body-condition index. Although we did not observe any sexual behavior from females in relatively low condition, two different males (incidentally, both from the low-condition group) (Fig. 1) manifested some sexual interest (Bh3: jerking) for two different females in low body condition. A male's body condition apparently did not influence his sexual behavior $(P>0.10)$ (Figs. 1 and 2$)$.

\section{Hormone Levels}

We found a highly significant difference in estradiol levels between high-condition and low-condition females (median test, $\chi^{2}=7.50, d l=1, P=0.006$ ) (Fig. 2). Although males in higher body condition tended to have higher levels of circulating testosterone than did thinner-bodied males, the difference did not reach statistical difference (median test, $\chi^{2}=3.44, d l=1$, $P=0.064$ ) (Fig. 2). This result may be due to our small sample size (notably, we failed to take blood from one male, reducing the sample size from 18 to 17) (Fig. 2). However, male body condition was positively correlated with plasma testosterone level (Spearman's correlation rank $\left.r_{\mathrm{s}}=0.55, N=7, P=0.02\right)$.

\section{Threshold Effect}

Within each sex, we tested to see if there was any clear-cut boundary in body condition between snakes 
that did versus did not express sexual behavior and did versus did not exhibit detectable levels of plasma sex steroids (Fig. 2). In females, our randomization tests showed that the probability of finding a pattern as extreme as that observed (i.e., no sexual behavior or detectable plasma estradiol in individuals with below-average body condition) was very low under the null hypothesis. For 10,000 random reassignments, this probability was 0.0245 and 0.0091 for sexual behaviors and estradiol levels, respectively. Hence, our data for female vipers support the concept of a body-condition threshold for the expression of sexual behavior and for estradiol production.

The situation was different in males. Four males in the low-condition group exhibited typical courtship behaviors (Bh3, Bh4), and two others were found coiled on one (or more) female(s). Hence, there was no threshold effect for sexual activity in this sex. The four matings occurred in "fat" male $\times$ "fat" female combination (Figs. 1 and 2). These four matings involved four different males and four different females. However, randomization $(N=$ 10,000 reassignments) showed that the probability of observing matings only in the high-condition males did not attain statistical significance $(P=0.191)$. Three lowcondition males also had detectable levels of plasma testosterone, but randomization tests showed that the pattern observed (i.e., no plasma value greater than 6.3 $\mathrm{ng} / \mathrm{ml}$, the highest value observed in the low-condition group, see Fig. 2) was statistically significant $(P=0.0158$, $N=10,000$ reassignments). This result suggests that males in high body condition were the only ones to produce large amounts of testosterone.

\section{DISCUSSION}

In most animal species (including the asp viper), male and female fitness is optimized in different ways. Reproductive success is strongly influenced by mating success in males and by egg production in females. In western central France, female vipers experience heavy costs of reproduction in terms of survival and energy balance. The majority $(75 \%)$ of the reproductive females do not survive through to the year after parturition, and all postparturient females are extremely emaciated (Bonnet et al., 2000b, 2001c). This low probability of survival and pronounced emaciation negatively affect a female's future reproductive success (Naulleau and Bonnet, 1996; Bonnet et al., 2001c). On average, female vipers reproduce every 3 years (if they survive long enough to do so!), accumulating energy reserves between breeding years (Saint
Girons, 1957). Male vipers, in contrast, can reproduce every year (Vacher-Vallas et al., 1999) and do not exhibit territorial behaviors. Thus, the fecundity-independent cost of male reproduction appear to be lower than that of females. We predicted that female vipers would exhibit a threshold level of energy reserves below which no reproduction would occur, while male vipers would exhibit a linear (or no) relationship between energy reserves and reproduction. Consistent with these predictions, female vipers in the low-bodycondition group failed to exhibit any reproductive characteristics, whereas males in both group did.

In our experiments, the only females that responded to courtship and accepted copulation were those with large body reserves and detectable plasma levels of estradiol. Previous studies on the same species have demonstrated that a similar body condition determines reproductive status (vitellogenic versus nonvitellogenic females) (Naulleau and Bonnet, 1996) and the occurrence of mating (Naulleau et al., 1999), and that plasma estradiol levels control the induction of vitellogenesis (Bonnet et al., 1994). Indeed, estradiol is the primary stimulus for vitellogenesis in many vertebrates (Ho et al., 1982; Callard, Riley, and Perez, 1990; Peyon, Baloche, and Burzawa-Gerard, 1993; Carnavelli, Mosconi, Angelini, Limatola, Ciarcia, and Polzonetti-Magni, 1991) and strongly influences sexual behavior in reptiles (Halpern, Morrell, and Pfaff, 1982; Mason, 1992; but see Whittier, Mason, and Crews, 1987; Saint Girons et al., 1993). Taken together, these data show that reproductive status and sexual behavior are tightly linked in female asp vipers. This relationship takes the form of a clear-cut threshold where circulating levels of estradiol, one of the "key" hormones for the mobilization of maternal reserves and for the expression of female sexual behaviors, are elevated only after maternal body reserves exceed a critical threshold. The same body condition threshold for reproduction has been shown in previous field studies. Our data do not allow us to tease apart the respective contributions of female attractiveness versus male motivation. Nonetheless they clearly show that mating is unlikely to happen in females below the threshold, despite the fact that most of them possess significant body reserves (Table 2) (Naulleau and Bonnet, 1996; Naulleau et al., 1999). Reproduction necessitates first the accumulation of abundant body reserves (the "capital") over prolonged periods (1-4 years) (Bonnet et al., 2000b) and then the massive mobilization of such reserves to fuel vitellogenesis.

Our prediction that there would be a minimum energy threshold for vitellogenesis and copulation 
was based on the life history of female vipers. Physiological regulation is assumed to be under strong selection to optimize the acquisition-allocation processes of reproduction. Although producing a large litter is more expensive than producing a small one (at least in terms of the energy content of the litter), the nonlinear relationship between reproductive effort and the sum of its associated costs may have favored the evolution of a high-body-condition threshold for reproduction. In female asp vipers, both the high survival and metabolic costs of reproduction are independent of the size of the litter (Bonnet et al., 2000c; Lourdais et al., 2001). Theoretically, the body-condition threshold enables females to save energy and to minimize survival costs during the 1- to 3-year phase of energy gathering between reproductive episodes. When sufficient reserves have been amassed, females become reproductive and optimize reproductive effort against the high metabolic and survival costs that are independent of fecundity by producing the maximum number of offspring (Bull and Shine, 1979).

In strong contrast to females, a high-body-condition threshold was not necessary for the induction of male reproductive activity in $V$. aspis. However, high levels of testosterone were found only in males with abundant body reserves. A rapid elevation of plasma testosterone levels stimulates sexual activity after winter emergence in male asp vipers (Fleury and Naulleau, 1987; Naulleau and Fleury, 1987; Naulleau et al., 1987; Saint Girons et al., 1993), as in many other snake species (Bona-Gallo, Licht, Mackenzie, and Lofts, 1980; Krohmer, Grassman, and Crews, 1987; Aldridge, Greenhaw, and Plummer, 1990; Bonnet and Naulleau, 1996). In addition, high levels of testosterone provoke a strong anorexia in the asp viper, under both natural and experimental conditions. This cessation of feeding results in a marked decrease of body reserves during the mating period (Bonnet, 1996; Vacher-Vallas, 1997). Males in high body condition mate-search more intensively than emaciated males, and can locate more reproductive females (Vacher-Vallas, 1997).

Male vipers may adjust their reproductive effort to their body fat reserves by producing quantities of testosterone proportional to the effort they can sustain without feeding. In support of this hypothesis, fat reserves are highly correlated with the mass of the testis (the source of testosterone) in the asp viper (Bonnet, 1996), and in a colubrid snake species as well (Bonnet and Naulleau, 1996). Radiotracking data gathered during the mating season indicate that males in high body condition search over larger areas than do males in lower condition, and hence encounter more females (Vacher-Vallas, 1997). We also found a positive correlation between early body condition and testosterone levels in males sampled in the field (Bonnet et al., 2000a). None of the studies provided any hint of a high-body-condition threshold that could separate reproductive from nonreproductive males. Extremely emaciated individuals may not produce detectable amounts of testosterone and probably do not court females, perhaps because their survival would be strongly jeopardized by further emaciation (unpublished). Although males in high condition were the only ones to mate under our experimental conditions, randomization tests did not falsify the possibility that relatively emaciated males might sometimes be successful as well. However, our experimental setup may have introduced bias in this respect. We presented males with a female in close proximity, and without rival males. Male vipers may modify their intensity of courtship in response to the numbers and sizes of rivals (as is true in garter snakes) (Shine et al., 2000a). If so, our setup may have encouraged courtship by emaciated males to a greater degree than is usually the case in natural settings. Plausibly, the effectiveness of courtship might also depend on a male's body condition. The intensity and frequency of the male's jerking movements could provide a female with information on the strength and stamina of the male. Body condition is correlated with muscle mass in male snakes (Bonnet, 1996), and recent work shows that heavierbodied males obtain more matings in another snake species (Shine et al., 2000b).

Regardless, these issues do not invalidate our main conclusion: male vipers did not demonstrate a critical threshold for the instigation of mating activity. Instead, males may adjust their reproductive effort facultatively, whereas a female commits herself to major investment whenever she "decides" to reproduce (although we doubt that most animals make conscious decisions). The capital versus income breeder dichotomy, where resources necessary for reproduction originate from body reserves versus from the food gathered at the time of reproduction (Drent and Daan, 1980; Stearns, 1992; Jönsson, 1997), offers a conceptual framework for this result. Capital breeders are expected to invest in reproduction only after enough body reserves (the capital) have been accumulated to reach a "body-condition threshold" (sensus Stearns, 1992). Although the influence of body condition on reproduction has been demonstrated in many species (Albon, Mitchell, Huby, and Brown, 1986; Reznick and Braun, 1987; DeRouen, Franke, Morisson, et al., 1994; Festa-Bianchet, Gaillard, and Jorgenson, 1998), the no- 
tion of a condition threshold stricto sensu is far less clear (review in Naulleau and Bonnet, 1996; Bonnet et al., 1998b). Our experimental data demonstrate the coexistence of two contrasting reproductive systems within a single capital-breeding snake species: a clearcut condition threshold in females versus a flexible system in males. Hormonal data mirror this behavioral dichotomy between the sexes, suggesting that neurophysiological regulatory mechanisms underlie these patterns (Sinervo and Svensson, 1998). Our results provide the first example in vertebrates of a sexual dimorphism in the relationship between body reserves and "reproductive decisions" (rigid vs gradual), at least in terms of sexual behaviors and sex steroid plasma levels.

Our data also highlight complications in the concepts of capital versus income breeding. For example, several mammals are classified as typical capital breeders (Festa-Bianchet et al., 1998) but recent reviews on captive and natural populations of mammals found no support for the widely accepted "adaptationist argument that females should delay ovulation until they have sufficient energy reserves to support pregnancy and lactation" (Bronson, 1998; Schneider, Zhou, and Blum, 2000). These animals also display ability to cancel, increase, or decrease reproductive effort at a later stage long after the initiation of reproduction per se. In this sense, capital breeding mammals may be similar to male asp vipers: individuals with more body reserves are more likely to reproduce, but do not require a threshold level of reserves to initiate reproduction (Bronson, 1998; this paper). Thus, they do not satisfy the "threshold" criterion for capital breeding (Stearns, 1992). In contrast, female asp vipers do satisfy this criterion.

Overall, the use of the term capital breeder requires further clarification if we are to compare reproductive tactics among diverse taxonomic groups. The time course over which energy is gathered versus expended is clearly a different issue from the notion of whether or not a critical resource threshold is needed prior to initiating reproduction. The two continua will be correlated (animals that rely on stored reserves will more often exhibit threshold effects) but there will be substantial diversity in this relationship. Our data provide a clear example of two sets of organisms (male and female asp vipers) that share many genes and live in the same places, but nonetheless display very different relationships in terms of the way in which a given level of energy investment influences reproductive output, depending on various facets of their biology. It would be interesting to repeat our study with a species that demonstrates male parental care or other fecundity-independent costs. In such a situation, we expect that a threshold effect will be observed in males, similar to that we have documented in female asp vipers. Similarly, in true "income breeders" we may see no threshold effect in females despite their investment into the clutch.

Our study provides information on connections between energy reserves, reproductive decisions, sexual behaviors, and underlying hormonal plasma levels. Snakes present several important advantages to explore such complex relationships among traits. First, ectothermic vertebrates like squamate reptiles exhibit a profoundly different metabolic machine when compared with endothermic vertebrates (Pough, 1980, 1983; Else and Hulbert, 1981; Hulbert and Else, 1981). Ectotherms, as low-energy systems, can present a total decoupling between the phase of energy gathering and the period during which energy is invested for reproduction (Secor et al., 1994; Bonnet, Shine, Naulleau, and Vacher-Vallas, 1998b). In strong contrast to what has been documented in endotherms (Bronsson, 1998; Schneider et al., 2000), a high body condition can be sufficient to initiate and fuel reproductive effort in snakes (Naulleau and Bonnet, 1996). In addition, female snakes do not provision their neonates after parturition, males generally do not exhibit territoriality or pair fidelity, and there is no forcible insemination. Overall, snakes offer a simple mating system where male and female fitness is optimized in very different ways: reproductive success is strongly influenced by mating success in males and by egg production in females (Devine, 1984; Madsen and Shine, 1993, 1994; Madsen et al., 1993).

\section{ACKNOWLEDGMENTS}

We thank T. Horan for inspiration, and M. Ladyman for help with English. We also thank Jubilation T. Wilmslow, Rex Cambag, Gisèle Gaboune, Chris Thiburce, and Jo Manix for discussion on the manuscript. We are grateful to Matthieu Guillemain who performed the randomization. Financial support was provided by the Conseil Général des Deux Sèvres (X.B.) and the ARC (R.S.). Two anonymous referees provided abundant and very helpful comments to improve the manuscript.

\section{REFERENCES}

Albon, S. D., Mitchell, B., Huby, B. J., and Brown, D. (1986). Fertility in female red deer (Cervus elaphus): The effects of body composition, age and reproductive status. J. Zool. 209, 447-460. 
Aldridge, R. D., Greenhaw, J. J., and Plummer, M. V. (1990). The male reproductive cycle of the Rough Green snake (Opheodrys aestivus). Amphibia-Reptilia 11, 165-172.

Bona-Gallo, A., Licht, P., Mackenzie, D. S., and Lofts, B. (1980). Annual cycles in levels of pituitary and plasma gonadotropin, gonadal steroids, and thyroid activity in the Chinese cobra (Naja naja). Gen. Comp. Endocrinol. 42, 477-493.

Bonnet, X. (1996). Gestion des réserves corporelles et stratégie de reproduction chez Vipera aspis. Unpublished thesis, Université de Lyon I.

Bonnet, X., and Naulleau, G. (1994). A body condition index (BCI) in snakes to study reproduction. C.R. Acad. Sci. 317, 34-41.

Bonnet, X., and Naulleau, G. (1996). Are body reserves important for reproduction in male dark green snakes (Coluber viridiflavus)? Herpetologica 52, 137-146.

Bonnet, X., Naulleau, G., and Mauget, R. (1994). The influence of body condition on $17 \beta$-estradiol levels in relation to vitellogenesis in female Vipera aspis (Reptilia, Viperidae). Gen. Comp. Endocrinol. 93, 424-437.

Bonnet X., Bradshaw, S. D., and Shine, R. (1998a). Capital versus income breeding: An ectothermic perspective. Oikos 83, 333-342.

Bonnet X., Shine R., Naulleau G., and Vacher-Vallas M. (1998b). Sexual dimorphism in snakes: Different reproductive roles favour different body plans. Proc. R. Soc. B 265, 1-5.

Bonnet, X., Naulleau, G., and Lourdais, O. (2000a). The benefits of complementary techniques: Using capture-recapture and physiological approaches to understand costs of reproduction in the asp viper. In G. Schuett and M. Höggren (Eds.), Biology of the Vipers, in press.

Bonnet, X., Naulleau, G., Shine, R., and Lourdais, O. (2000b). What is the appropriate time scale for measuring costs of reproduction in a capital breeder such as the asp viper? Evol. Ecol. 13, 485-497.

Bonnet, X., Naulleau, G., Shine, R., and Lourdais, O. (2000c). Reproductive versus ecological advantages to larger body size in female Vipera aspis. Oikos 89, 509-518.

Bonnet, X., Naulleau, G., Shine, R., and Lourdais, O. (2001a). Shortterm versus long-term effects of food intake on reproductive output in a viviparous snake (Vipera aspis). Oikos 92, 297-308.

Bonnet, X., Naulleau G., Bradshaw D., and Shine R. (2001b). Changes in plasma progesterone in relation to vitellogenesis and gestation in the viviparous snake, Vipera aspis. Gen. Comp. Endocrinol. 121, 84-94.

Bonnet, X., Lourdais O., Shine R., and Naulleau G. (2001c). Reproduction in snakes (Vipera aspis): costs, currencies and complications. Ecology, in press.

Bronson, F. H. (1998). Energy balance and ovulation: small cages versus natural habitats. Reprod. Fertil. Dev. 10, 127-137.

Bull, J. J., and Shine, R. (1979). Iteroparous animals that skip opportunities for reproduction. Am. Nat. 114, 296-316.

Callard, I. P., Riley, D., and Perez, L. (1990). Vertebrate vitellogenesis: Molecular model for multihormonal control of gene regulation. Prog. Comp. Endocrinol. 1990, 343-348.

Carnavelli, O., Mosconi, G., Angelini, F., Limatola, E., Ciarcia, G., and Polzonetti-Magni, A. (1991). Plasma vitellogenin and $17 \beta-$ estradiol levels during the annual reproductive cycle of Podarcis sicula. Gen. Comp. Endocrinol. 84, 337-343.

Cherel, Y., Mauget, R., Lacroix, A., and Gilles, J. (1994). Seasonal and fasting-related changes in circulating gonadal steroids and prolactin in king penguins, Aptenodytes patagonicus. Physiol. Zool. 67, 1154-1173.

Crowley, P. H. (1992). Resampling methods for computation-intensive data analyses in ecology and evolution. Annu. Rev. Ecol. Systemat. 23, 405-447.
DeRouen, S. M., Franke, D. E., Morisson, D. G., Wyatt, W. E., Coombs, D. F., White, T. W., Humes, P. E., and Greene, B. (1994). Prepartum body condition and weight influences on reproductive performance of first-calf beef cows. J. Anim. Sci. 72, 1119-1125.

Devine, M. C. (1984). Potential for sperm competition in reptiles: Behavioral and physiological consequences. In R. L. Smith (Ed.), Sperm Competition and the Evolution of Animal Mating Systems, pp. 509-521. Academic Press, Orlando, FL.

Drent, R. H., and Daan, S. (1980). The prudent parent: Energetic adjustments in avian breeding. Ardea 68, 225-252.

Else, P. L., and Hulbert, A. J. (1981). Comparison of the "mammal machine" and the "reptile machine": Energy production. Am. J. Physiol. 240, R3-R9.

Festa-Bianchet, M., Gaillard, J. M., and Jorgenson, J. T. (1998). Massand density-dependent reproductive success and reproductive costs in a capital breeder. Am. Nat. 152, 367-379.

Fleury, F., and Naulleau, G. (1987). Relations entre l'hivernage et la reprise des activités endocrines, testiculaire et thyroïdienne, chez Vipera aspis L. (Reptilia, Viperidae). Gen. Comp. Endocrinol. 68, 271-277.

Frisch, R. E. (1978). Menarche and fatness: Reexamination of the critical body composition hypothesis. Science 200, 1509-1513

Frish, R. E., and McArthur, J. (1974). Menstrual cycles: Fatness as a determinant of minimum weight for height necessary for their maintenance or onset. Science 215, 949-951.

Fukada, H. (1959). A method for detecting copulated female snakes. Herpetologica 15, 181-182.

Gillingham, J. C. (1977). Further analysis of reproductive behavior in the Western fox snake, Elaphe v. vulpina. Herpetologica 33, 349353.

Guillemain, M., Loreau, M., and Daufresne, T. (1997). Relationships between the regional distribution of carabid beetles (Coleoptera, Carabidae) and the abundance of their potential prey. Acta Oecol. 18, 465-483.

Halpern, M., Morrell, J. I., and Pfaff, D. W. (1982). Cellular $\left[{ }^{3} \mathrm{H}\right] \mathrm{es}-$ tradiol and $\left[{ }^{3} \mathrm{H}\right]$ testosterone localization in the brains of garter snakes: An autoradiographic study. Gen. Comp. Endocrinol. 46, 211-224.

Hirshfield, M. F., and Tinkle, D. W. (1975). Natural selection and the evolution of reproductive effort. Proc. Natl. Acad. Sci. USA 72, 2227-2231.

Ho, S. M., Kleis-San Francisco, S., McPherson, R., Heiserman, G. J., and Callard, I. P. (1982). Regulation of vitellogenesis in reptiles. Herpetologica 38, 40-50.

Hulbert, A. J., and Else, P. L. (1981). Comparison of the "mammal machine" and the "reptile machine": Energy use and thyroid activity. Am. J. Physiol. 241, R350-R356.

Jayne, B. C., and Bennett, A. F. (1990). Selection on locomotor performance capacity in a natural population of garter snakes. Evolution 44, 1204-1229.

Jönsson, K. I. (1997). Capital and income breeding as alternative tactics of resource use in reproduction. Oikos 78, 57-66.

Krohmer, R. W., Grassman, M., and Crews, D. (1987). Annual reproductive cycle in the male red-sided garter snake, Thamnophis sirtalis parietalis: Field and laboratory studies. Gen. Comp. Endocrinol. 68, 64-75.

Larsen, L. O. (1980). Physiology of adult lampreys, with special regard to natural starvation, reproduction, and death after spawning. Can. J. Fish. Aquat. Sci. 37, 1762-1779.

Lourdais O., Bonnet X., and Doughty P. (2001). Costs of anorexia during pregnancy in a viviparous snake (Vipera aspis). J. Exp. Zool., in press. 
Madsen, T., and Shine, R. (1993). Costs of reproduction in a population of European adders. Oecologia 94, 488-495.

Madsen, T., and Shine, R. (1994). Components of lifetime reproductive success in adders, Vipera berus. J. Anim. Ecol. 63, 561-568.

Madsen, T., and Shine, R. (1999). The adjustment of reproductive threshold to prey abundance in a capital breeder. J. Anim. Ecol. 68, 571-580.

Madsen, T., Shine, R., Loman, J., and Håkansson, T. (1993). Determinants of mating success in male adders, Vipera berus. Anim. Behav. 45, 491-499.

Mason, R. T. C. (1992). Reptilian pheromones. In C. Gans and D. Crews (Eds.), Hormones, Brain, and Behavior, pp. 114-228. Univ. of Chicago Press, Chicago.

Monaghan, P., and Nager, R. G. (1997). Why don't birds lay more eggs? Trends Ecol. Evol. 12, 270-274.

Moore, M. C., and Lindzey, J. (1992). The physiological basis of sexual behavior in male reptiles. In C. Gans and D. Crews (Eds.), Hormones, Brain, and Behavior, Vol. 18: Physiology of the Reptila, pp. 70-113. Univ. of Chicago Press, Chicago.

Morris, D. W. (1987). Optimal allocation of parental investment. Oikos 49, 332-339.

Morris, D. W. (1992). Optimum brood size: Tests of alternative hypotheses. Evolution 46, 1848-1861.

Naulleau, G. (1997). La vipère aspic. Eveil Nature, Saint Yrieix.

Naulleau, G., and Bonnet, X. (1996). Body condition threshold for breeding in a viviparous snake. Oecologia 107, 301-306.

Naulleau, G., and Fleury, F. (1987). Relations entre l'hivernage et la reprise des activités endocrines testiculaires et thyroïdienne, chez Vipera aspis L. (Reptilia, Viperidae). Gen. Comp. Endocrinol. 68, 271-277.

Naulleau, G., Fleury, F., and Boissin, J. (1987). Annual cycles in plasma testosterone and thyroxine for the male aspic viper, Vipera aspis L. (Reptilia, Viperidae), in relation to the sexual cycle and hibernation. Gen. Comp. Endocrinol. 65, 254-263.

Naulleau, G., Bonnet, X., Vacher-Vallas, M., Shine, R., and Lourdais, O. (1999). Does less than annual production of offspring by female vipers (Vipera aspis) mean less than annual mating? J. Herpetol. 33, 688-691.

Peyon, P., Baloche, S., and Burzawa-Gerard, E. (1993). Synthesis of vitellogenin by eel (Anguilla anguilla L.) hepatocytes in primary culture: Requirement of $17 \beta$-estradiol-priming. Gen. Comp. Endocrinol. 91, 318-329.

Pough, F. H. (1980). The advantages of ectothermy for tetrapods. Am. Nat. 115, 92-112.

Pough, F. H. (1983). Amphibians and reptiles as low-energy systems. In W. P. Aspey, and S. I. Lustick (Eds.), Behavioural Energetics: The Cost of Survival in Vertebrates, pp. 141-188. Academic Press, New York.

Reznick, D. N., and Braun, B. (1987). Fat cycling in the mosquitofish (Gambusia affinis): Fat storage as a reproductive adaptation. Oecologia 73, 401-413.

Reznick, D. N., and Yang, A. P. (1993). The influence of fluctuating resources on life history: Patterns of allocation and plasticity in female guppies. Ecology 74, 2011-2019.

Roff, D. A. (1981). Reproductive uncertainty and the evolution of iteroparity: Why don't flatfish put all their eggs in 1 basket? Can. J. Fish. Aquat. Sci. 38, 968-977.
Saint Girons, H. (1952). Ecologie et éthologie des vipères de France. Ann. Sci. Nat. Zool. 14, 265-343.

Saint Girons, H. (1957). Le cycle sexuel chez Vipera aspis (L) dans l'ouest de la France. Bull. Biol. Fr. Belg. 91, 284-350.

Saint Girons, H. (1996). Structure et évolution d'une petite population de Vipera aspis (L.) dans une région de bocage de l'ouest de la France. Rev. Ecol. 51, 223-241.

Saint Girons, H., Bradshaw, S. D., and Bradshaw, F. J. (1993). Sexual activity and plasma levels of sex steroids in the aspic viper Vipera aspis L. (Reptilia, Viperidae). Gen. Comp. Endocrinol. 91, 287-297.

Schaffer, W. M. (1974). Optimal reproductive effort in fluctuating environment. Am. Nat. 108, 783-790.

Schneider, J. E., Zhou, D., and Blum, R. M. (2000). Leptin and metabolic control of reproduction. Horm. Behav. 37, 306-326.

Schuett, G. W. (1997). Body size and agonistic experience affect dominance and mating success in male copperheads. Anim. Behav. 54, 213-224.

Schuett, G. W., and Gillingham, J. C. (1988). Courtship and mating behavior in the copperhead, Agkistrodon contortrix. Copeia 1988, 374-381.

Secor, S. M., Stein, E. D., and Diamond, J. M. (1994). Rapid upregulation of snake intestine in response to feeding: A new model of intestinal adaptation. Am. J. Physiol. 266, G695-G705.

Shine, R., O'Connor, D., and Mason, R. T. (2000a). Female mimicry in gartersnakes: Behavioral tactics of "she-males" and the males that court them. Can. J. Zool., in press.

Shine, R., Olsson, M. M., Moore, I., Le Master, M. P., Greene, M., and Mason, R. T. (2000b). Body size enhances mating success in male gartersnakes. Anim. Behav. 59, F4-F11.

Shine, R., Harlow, P. S., LeMaster, M. P., Moore, I., and Mason, R. T. (2000c). The transvestite serpent: Why do male gartersnakes court (some) other males? Anim. Behav. 59, 349-359.

Sinervo, B., and Svensson, E. (1998). Mechanistic and selective causes of life-history trade-offs and plasticity. Oikos 83, 432-442.

Statistica for Windows, Vol. I: General Conventions and Statistics. (1995). StatSoft, Inc., Tulsa, OK.

Stearns, S. C. (1992). The Evolution of Life Histories. Oxford Univ. Press, New York.

Vacher-Vallas, M. (1997). Comportement sexuel, condition corporelle et stratégie de reproduction chez Vipera aspis: Étude en milieu naturel. Unpublished thesis, Université Francois Rabelais, Tours.

Vacher-Vallas, M., Bonnet, X., and Naulleau, G. (1999). Relations entre les comportements sexuels et les accouplements chez Vipera aspis: Étude en milieu naturel. Rev. Ecol. Terre Vie 54, 375-391.

Walker, S. E., and Ford, N. B. (1996). Courtship and mating behavior in the brown house snake Lamprophis fulginosus. J. Herpetol. 30, 416-418.

Whittier, J. M., Mason, R. T., and Crews, D. (1987). Plasma steroid hormone levels of female red-sided garter snakes, Thamnophis sirtalis parietalis: Relationship to mating and gestation. Gen. Comp. Endocrinol. 67, 33-43.

Winkler, D. W., and Wallin, K. (1987). Offspring size and number: A life history model linking effort per offspring and total effort. Am. Nat. 129, 708-720.

Young, T. P. (1990). Evolution of semelparity in Mount Kenya lobelias. Evol. Ecol. 4, 157-172. 